\title{
A estrutura do Sistema Público de Escrituração Digital (SPED): um estudo das novas obrigações
}

\author{
Suzete Antonieta Lizote \\ Diego Menin Mariot ${ }^{2}$
}

\section{RESUMO}

O Sistema Público de Escrituração Digital (SPED) é um instrumento de acompanhamento e fiscalização criado pelo governo, cujo principal objetivo é promover a integração dos fiscos, mediante a padronização e compartilhamento das informações contábeis e fiscais. Uma das grandes preocupações das empresas se refere às diversas informações a serem prestadas periodicamente à fiscalização, ressaltando-se que esse novo sistema traz relevantes mudanças e impacta diretamente com tais obrigações. Diante desse contexto, este estudo tem como objetivo descrever a estrutura do projeto SPED e as novas obrigações pertinentes previstas na legislação. Metodologicamente com relação à forma de abordagem do problema, caracteriza-se como qualitativa. Como a pesquisa foi desenvolvida e embasada com estudo da legislação federal e estadual em vigor, quanto aos seus objetivos, classifica-se como descritiva, e do ponto de vista dos procedimentos técnicos, considera-se um estudo bibliográfico. As conclusões demonstram que o fisco estruturou o SPED de forma eficaz e com validade jurídica, pela assinatura eletrônica, efetivando o recebimento de diversos tipos de informações fiscais e contábeis das empresas. Também ficou evidente a não descontinuidade com a exigência de entrega das obrigações acessórias anteriores, ocasionando casos de duplicidade de dados.

Palavras-chave: Sistema Público de Escrituração Digital. Obrigações acessórias. Escrituração Fiscal Digital.

\section{INTRODUÇÃO}

A ciência contábil tem como um de seus principais objetivos a mensuração e avaliação do patrimônio, visando levantar dados tempestivos e fidedignos embasados nas informações das entidades, para que seus diversos usuários possam utilizá-la como instrumento principal de apoio à tomada de decisões (IUDíCIBUS, 1997).

Esses usuários são os proprietários, sócios, credores, investidores e todos que desejem conhecer a situação econômica e financeira da entidade em questão. Além desses, o governo também tem grande interesse na escrita contábil das empresas. De acordo com Hastings (2007), o interesse fundamental dos órgãos arrecadadores do governo, nos três níveis administrativos, é poder apurar a renda tributável das organizações.

Dentro das rotinas de trabalho desenvolvidas pelo departamento fiscal de uma empresa ou organização contábil, sem dúvida, as obrigações acessórias exigidas pelo fisco, às quais as empresas estão sujeitas, representam as tarefas que, infelizmente, ocupam o maior tempo do profissional contábil. O programa SPED, o qual foi implantado e está sendo ampliado pelo governo federal em conjunto com o governo estadual, tem por finalidade principal a fiscalização mais ágil em torno das empresas, buscando minimizar a sonegação fiscal e

1 Universidade Vale do Itajaí - lizote@univali.br

2 Universidade Vale do Itajaí - diegomariot@univali.br 
uma acentuada diminuição nas obrigações acessórias.

Diante desse contexto, este estudo, caracterizado como pesquisa bibliográfica, procura responder ao seguinte questionamento: Como se encontra estruturado o SPED e quais são as novas obrigações previstas? Assim, tem como objetivo descrever a estrutura do projeto SPED e as novas obrigações pertinentes, previstas na legislação; realizar levantamento da legislação, a fim de conhecer a base conceitual sobre o tema objeto do estudo; identificar os novos subprojetos do SPED previstos na legislação, bem como seu funcionamento; verificar as principais obrigações acessórias com informações redundantes, pela não dispensa por parte do fisco, e analisar o novo sistema de registro das informações mercantis, em relação a projetos futuros. Essas foram as etapas que nortearam o seu desenvolvimento.

0 tema desta pesquisa foi escolhido em virtude da magnitude das mudanças a serem implantadas nas organizações, os prazos estipulados para a obrigatoriedade da utilização plena do SPED e a constante evolução no sentido de buscar cada vez mais informações sobre as operações fiscais (tributárias) e contábeis das empresas. Dessa forma, espera-se que os resultados evidenciados possam trazer contribuições para os profissionais da contabilidade e para as empresas em geral, no que se refere ao conhecimento da proporção do projeto e às novas obrigações exigidas pelos órgãos governamentais.

\section{EVOLUÇÃO DA CONTABILIDADE}

A contabilidade no Brasil iniciou-se a partir da época colonial, representada pela evolução da sociedade e das alfândegas que surgiram no ano de 1530, com influência portuguesa. Porém, foi só em 1808, com a chegada da família real do reinado de João I, que ocorreu um desenvolvimento socioeconômico na colônia. Foram criados os portos, onde se passou a comercializar diversos produtos; foi fundado o Banco do Brasil e, consequentemente, iniciou-se a emissão do papel moeda.

Com o crescimento dos negócios e dos órgãos públicos, surgiu a necessidade de um profissional de contabilidade, e as escriturações das contas só poderiam ser feitas pelas pessoas que estudassem aula de comércio. Apesar de todos os estímulos da área pública, o ensino comercial levou quase cem anos para se estruturar, e só em 1902, depois do movimento dos guarda-livros, foi fundada a escola de prática de comércio, formando profissionais com excelência no ensino.

Em 1850, o código civil qualificou os guarda-livros como prepostos dos comerciantes, ressaltando a legalidade da profissão de contador, e, em 1869, foi criada a Associação Brasileira dos Guarda-Livros da corte, sendo reconhecido oficialmente com um decreto imperial, assim tornando-o o primeiro profissional liberal do Brasil.

Finalmente, pelo Decreto-Lei no 9.295, de 27 de maio de 1946, foram criados os Conselhos Federais e Regionais de Contabilidade, com obrigação de fiscalizar e regular a profissão contábil. Foi definido o perfil do contabilista, que, daquele momento, contadores seriam graduados em cursos de universidade de Ciências Contábeis; técnicos em contabilidade eram de níveis médios; e os guarda-livros não tinham escolaridade formal. Em 1981, o Conselho Federal de Contabilidade estabeleceu as Normas Brasileiras de Contabilidade (NBC), dividindo-as em normas Brasileiras de Contabilidade - Técnicas (NBC-T) e Normas Brasileiras de Contabilidade - Profissionais (NBC-P), quando também foram criados os princípios contábeis (REIS; SILVA, 2007).

Diante de tantas Normas e Princípios, o profissional da área contábil, conforme argumentam Favero et al. (2009), deve ter amplo conhecimento e qualificação, para atender com eficácia e eficiência às constantes mudanças da legislação e às necessidades do mercado, que precisam das informações, de forma tempestiva, auxiliando as tomadas de decisões.

\subsection{A contabilidade e os sistemas de informação}

Com o desenvolvimento das atividades comerciais e com o crescimento e diversificação da economia global, a ciência contábil foi se adaptando ao novo cenário, tornando-se a cada dia mais imprescindível às administrações tanto públicas, quanto privadas. Com o aumento considerável de registros para acompanhar e mensurar o resultado e o patrimônio das entidades, a tecnologia da informação passou a ser utilizada 
intensivamente no exercício da profissão contábil (STAINER, 1997).

Nessa linha de pensamento, Gil (1992) argumenta que, na era da informação, as empresas estão percebendo que o sucesso ou fracasso depende cada vez mais de como gerenciam e usam as informações. Corroboram com a ideia Moscove, Simkin e Bagranoff (2002), evidenciando que uma das características desta era é o emprego da maior parte da força de trabalho como trabalhadores de conhecimento.

Com as mudanças trazidas pelo desenvolvimento tecnológico, o Governo Federal, sentindo a necessidade de aprimoramento de suas ferramentas de fiscalização, unificou seus bancos de dados para compartilhamento das informações entre os poderes públicos de todas as esferas, embasado na Emenda Constitucional no 42/2003, que introduziu o inciso XXII ao art. 37 da Constituição Federal, determinando que as administrações tributárias da União, dos Estados, do Distrito Federal e dos Municípios atuem de forma integrada, inclusive com o compartilhamento de cadastros e de informações fiscais. Com essa alteração na constituição, o fisco criou o embasamento legal necessário e a prova de qualquer contestação por parte das empresas para embasar a troca de informações que deu a origem aos trabalhos do SPED e seus subprojetos.

\subsection{Sistema Público de Escrituração Digital (SPED)}

O SPED, conforme o art. $2^{\circ}$, do Decreto no $6.202 / 2007$, é um instrumento que unifica as atividades de recepção, validação, armazenamento e autenticação de livros e documentos que integram a escrituração comercial e fiscal dos empresários e das sociedades empresárias, mediante fluxo único, computadorizado, de informações. Complementa Girotto (2008), evidenciando que se refere a um método eletrônico moderno que unifica os procedimentos de recepção, validação, armazenamento e autenticação de livros e documentos que integram a escrituração comercial e fiscal dos empresários e das sociedades empresárias.

Dessa forma, observa-se que se trata de um projeto desenvolvido pelo Governo Federal, com participações das administrações dos Estados, Municípios e Distrito Federal, sendo dividido em diversos subprojetos. Neste estudo, serão abordados os projetos em andamento: Escrituração Contábil Digital (ECD), Escrituração Fiscal Digital (EFD), Nota Fiscal Eletrônica (NF-e) e Escrituração Fiscal Digital - Contribuições (EFD-Contribuições); e os novos projetos: Bloco P - Apuração da Contribuição Previdenciária sobre a Receita Bruta (parte integrante da EFD-Contribuições) e Escrituração Fiscal Digital - Social (EFD-Social).

Essa iniciativa visa dar mais agilidade e segurança na recepção e no processamento dos dados informados periodicamente pelos contribuintes, possibilitando a identificação de atividades tributárias ilícitas de forma automática e eletrônica por meio de cruzamento de informações. Dessa maneira, proporciona aos governos federal e estadual um maior controle dos processos relacionados às medidas antissonegação (DUARTE, 2009).

Destaca Young (2009) que, com a criação do SPED, o Governo propicia maior controle e agilidade na fiscalização das informações contábeis e fiscais das empresas por meio de compartilhamento de arquivos eletrônicos, disponibilizados nos níveis de governo federal, estadual e municipal, ao mesmo tempo em que promove uniformidade e racionalização no cumprimento das diversas obrigações acessórias por parte das empresas para com o Fisco.

Diante dessas afirmações, infere-se que, com as informações em meio magnético, o Fisco tornará mais ágil a identificação de fraudes, havendo igualmente a redução de custos com a dispensa de emissão e armazenamento de documentos em papel, contribuindo, desse modo, com a preservação do meio ambiente.

\subsection{Escrituração Contábil Digital (ECD)}

Seguindo o ideal do projeto SPED, sendo um de seus subprojetos, a ECD visa basicamente obter os livros e informações contábeis dos contribuintes por meio de arquivo eletrônico, facilitando a fiscalização e o acompanhamento da evolução do patrimônio das entidades.

A Instrução Normativa RFB no 787/2007 institui e regula a ECD trazendo os prazos para apresentação:

Art. 3ํㅡ - Ficam obrigadas a adotar a ECD, nos termos do art. 2을 do Decreto no 6.022, de 2007:

I - em relação aos fatos contábeis ocorridos a partir de $1^{\text {o }}$ de janeiro de 2008, as pessoas jurídicas sujeitas a acompanhamento econômico-tributário diferenciado, nos termos da Portaria RFB no 11.211, de 7 de novembro de 2007, e sujeitas à tributação do imposto de renda com base no lucro real;

II - em relação aos fatos contábeis ocorridos a partir de 1ํ de janeiro de 2009, as demais pessoas 
Conforme o art. 2ํ da Instrução Normativa RFB nํ787/2007, a ECD compreenderá a versão digital dos seguintes livros:

a) livro diário e auxiliares, se houver

b) livro razão e seus auxiliares, se houver;

c) livro balancetes diários, balanços e fichas de lançamento comprobatórias dos assentamentos neles transcritos.

Para garantir a legitimidade e integridade das informações transmitidas pela ECD, será usada a tecnologia de certificação digital, com segurança mínima do tipo A3, emitida por entidade credenciada pela Infraestrutura de Chaves Públicas Brasileiras (ICP-Brasil) com a finalidade de atestar a autoria do documento digital.

Conforme a Instrução Normativa DNRC no 107/2008, o livro digital será enviado pelo empresário ou sociedade empresária ao SPED com o respectivo requerimento de autenticação à Junta Comercial, ficando o livro disponível nesse Serviço para então ser visualizado pelo autenticador da Junta Comercial.

$\S 1^{\mathrm{o}}$ - 0 livro digital, mediante solicitação do autenticador ao Sped, será disponibilizado para ser visualizado, por tempo suficiente para esse procedimento, sendo vedado o acesso à visualização após a sua autenticação $\S 2^{\circ}$ - 0 pagamento do preço do serviço deverá ser efetuado previamente à sua solicitação mediante recolhimento por guia de arrecadação a ser disponibilizada pela Junta Comercial ao interessado. $3^{\circ}$ - 0 requerimento mencionado no caput deste artigo conterá o número da guia de recolhimento, consoante sistemática adotada pela Junta Comercial, que disponibilizará informação a respeito, quando necessário (BRASIL, 2008).

Não serão permitidos, depois de homologados os livros contábeis eletrônicos pela Junta Comercial, que continuará a desenvolver sua função de registrá-los, retificações sob nenhuma hipótese. As possíveis falhas ou erros na escrituração contábil terão de ser corrigidas no exercício atual, ou seja, quando constatados, como ajustes de exercícios anteriores, conforme as Normas Brasileiras de Contabilidade preconizam.

Assim sendo, Mariano e Azevedo (2009) afirmam que, com as informações de toda a escrita contábil detalhada em único e imenso banco de dados, é perfeitamente possível e relativamente fácil para o fisco cruzar com as demais informações prestadas a fim de identificar possíveis inconsistências nas peças contábeis.

Duarte (2009) exemplifica a real mudança para as empresas, argumentando que poucos perceberam que o mais importante é a contabilidade e não a tecnologia. A escrituração contábil deve refletir as operações reais da empresa: faturamento, movimentação de estoque, finanças, entre outras. 0 desafio em questão é ter a contabilidade coerente, real e íntegra; auditável eletronicamente pela empresa e pelo fisco.

Uma das mais tradicionais obrigações acessória - a Declaração de Imposto de Renda da Pessoa Jurídica (DIPJ) - exige que os contribuintes prestem diversas informações da escrita contábil, e as empresas tributadas pelo Lucro Real continuam obrigadas a informá-la anualmente, mesmo tendo declarado todos esses dados na ECD. É uma tendência que essa informação deixe de ser exigida, pois as informações se tornam redundantes.

\subsection{Escrituração Fiscal Digital (EFD)}

A EFD, instituída pelo Convênio de ICMS no 143/2006, de 20 de dezembro de 2006, é parte integrante do projeto SPED, e seu fundamento implica a entrega de arquivos digitais de todas as informações fiscais, informações estas que eram apresentadas anteriormente na forma de livros impressos.

Materializada em um arquivo digital, tal escrituração, segundo Young (2009), constitui-se em um conjunto de escrituração de documentos fiscais e outras informações de interesse dos Fiscos das Unidades da Federação e da Secretaria da Receita Federal do Brasil, bem como no registro e apuração de impostos referentes às operações e prestações praticadas pelo contribuinte.

Nessa parte do processo, explica Brito (2011), o contribuinte irá, por meio de sua base de dados, gerar um arquivo digital com informações de suas movimentações fiscais, e o arquivo contemplará informações de todos os documentos fiscais de entrada, saída, registros de apuração do ICMS e IPI, livros de registro de inventário e outras informações solicitadas pelas administrações tributárias coordenadas pela Receita Federal do Brasil conforme leiaute predefinido.

Após a geração do arquivo no formato de texto, ele deverá ser validado no Programa Validador e Assinador (PVA) disponibilizado pela Receita Federal do Brasil e, assim, deverá ser encaminhado para a Receita, via internet. Cada Estado estipulou seus cronogramas de obrigatoriedade. 


\subsection{Nota Fiscal eletrônica (NF-e)}

Sendo a primeira ação que foi tomada e a entrar em funcionamento no projeto SPED, a NF-e consiste na emissão de uma nota fiscal de forma digital, com existência somente eletrônica, por meio de um arquivo no formato XML (Extensible Markup Language) substituindo as então notas fiscais impressas de modelo 1 e 1-A, tendo sua validade jurídica garantida pela assinatura digital do emitente.

O intuito do Governo Federal, em conjunto com os governos estaduais, na criação da NF-e, foi de facilitar os processos de fiscalização. Com a implantação da NF-e, o governo terá todas as informações da nota fiscal, antes mesmo de a mercadoria sair do estabelecimento, ou seja, antes da ocorrência do fato gerador, tendo com exatidão todos os dados da movimentação de produtos, tributação e valores de faturamento em tempo real. Outras finalidades são a redução de custo operacional (redução da utilização de papel), a diminuição da sonegação e o aumento da arrecadação com a movimentação das mercadorias.

Em 2006, teve início de forma gradual, para as empresas selecionadas no projeto-piloto, sendo dezenove empresas de cinco Estados; em 2007, houve um movimento de massificação, com a entrada de novas empresas e novos Estados. Com base nas publicações dos Protocolos de ICMS da legislação federal, cada Estado definiu e divulgou a relação nominal de empresas com atos próprios.

A NF-e vem evoluindo constantemente, sendo adaptada às novas realidades e situações do mercado e para evitar fraudes que porventura sejam praticadas visando à evasão fiscal. Com a Nota Técnica 2012/002 publicada em março de 2012, o fisco instituiu os Eventos de Confirmação, cuja principal ideia é de que o destinatário da NF-e se manifeste, seja confirmando ou não sua participação na operação, com mensagens assinadas digitalmente.

\subsection{Escrituração Fiscal Digital - Contribuições (EFD-Contribuições)}

Instituída pela Instrução Normativa RFB no⒈052, de 5 de julho de 2010, a EFD-Contribuições, inicialmente criada e chamada de EFD PIS-Cofins, foi idealizada para atender às necessidades do fisco relativamente à informação da composição detalhada da base de cálculo de créditos e débitos dessas duas contribuições as quais não tinham nenhum padrão definido de modelo de livro de apuração, a exemplo do Livro de Apuração do Lucro Real (Lalur), Livro de Apuração do IPI e Livro de Apuração do ICMS.

De acordo com Mariano e Azevedo (2009), A EFD-Contribuições é um arquivo digital instituído no SPED, a ser utilizado pelas pessoas jurídicas de direito privado na escrituração da Contribuição para o PIS/PASEP e da COFINS, nos regimes de apuração não cumulativo e/ou cumulativo, com base no conjunto de documentos e operações representativos das receitas auferidas, bem como dos custos, despesas, encargos e aquisições geradores de créditos da não cumulatividade.

Conforme disciplina a Instrução Normativa RFB no 1.052 , de 5 de julho de 2010, estão obrigadas a adotar a EFD-Contribuições, conforme cronograma atualizado pela Instrução Normativa RFB no 1.218, de 2011: (I) em relação aos fatos geradores ocorridos a partir de $1^{0}$ de janeiro de 2012, as pessoas jurídicas sujeitas à tributação do Imposto sobre a Renda com base no Lucro Real; (II) em relação aos fatos geradores ocorridos a partir de $1^{\circ}$ de julho de 2012, as demais pessoas jurídicas sujeitas à tributação do Imposto sobre a Renda com base no Lucro Presumido ou Arbitrado; (III) em relação aos fatos geradores ocorridos a partir de 10 de julho de 2012, as pessoas jurídicas referidas nos $§ \S 6^{\circ}$, 8o e 9o do art. 3ํㅡ da Lei no 9.718, de 27 de novembro de 1998, e na Lei ${ }^{\circ}$ 7.102, de 20 de junho de 1983 (BRASIL, 2011).

Todos os documentos da escrita fiscal dos contribuintes representativos de receita (saídas ou prestações) devem ser declarados, independentemente de a operação ser tributada ou não. Já no caso dos documentos de entrada (mercadorias e serviços), estes só devem ser declarados na escrituração da EFD-Contribuições se forem objeto de apropriação de crédito.

A RFB criou primeiramente a EFD do ICMS/IPI contendo informações básicas da apuração do PIS e COFINS; porém, como ficou a cargo de cada Estado efetivar o início da obrigatoriedade, a receita percebeu o fato que várias unidades da federação estavam protelando o início ou até mesmo deixando em segundo plano e decidiu criar uma escrituração totalmente separada do ICMS e IPI, exclusiva para seus fins e impôs a obrigatoriedade em nível nacional, obrigando as empresas a cumprirem o cronograma, mesmo com várias dificuldades de implantação e entendimento na nova ferramenta. 
Outro fator que prejudicou as empresas é a complexidade do emaranhado de normas jurídicas que norteiam essas contribuições. Teria sido prudente, antes de criar todo um sistema complexo e de difícil desenvolvimento, promover a simplificação tributária, mediante uma reforma na legislação ou até mesmo com a criação de um regulamento, para auxiliar os contribuintes.

O Demonstrativo de Apuração das Contribuições Sociais (DACON), exigido mensalmente das empresas, traz as mesmas informações da EFD-Contribuições, só que de forma sintética, por totais da base de cálculo e o montante de impostos devidos.

\subsubsection{Apuração da contribuição previdenciária sobre a receita bruta (Bloco P da EFD-Contribuições) escrituração da receita}

Com a publicação da Lei no 12.546, de 14 de dezembro de 2011, o Governo Federal mudou a forma de tributação da parte patronal devida à Previdência Social (alíquota de 20\%) que incidia sobre a folha de pagamento e, agora, para alguns setores, incide diretamente sobre a receita bruta auferida mensalmente.

Uma novidade relativamente à EFD-Contribuições é a exigência das informações do Bloco P, criado exclusivamente para que os contribuintes declarem os valores devidos à Previdência Social sobre sua receita bruta.

Conforme Brasil (2012), o guia prático da EFD-Contribuições, versão 1.0.7 atualizada em maio de 2012, a escrituração do Bloco "P" será específica para a apuração da Contribuição Previdenciária sobre Receita, efetuada pela pessoa jurídica de forma autônoma e independente da escrituração de apuração do PIS/PASEP e da COFINS, constante nos Blocos "A", "C", "D", "F" e "M". Trata-se de nova contribuição, exigível em relação aos fatos geradores a ocorrer a partir de março de 2012, não guardando a escrituração do Bloco "P" qualquer correlação ou vinculação com os registros informados nos referidos blocos.

Essa redução da carga tributária é chamada pelo Governo Federal de "desoneração da folha de pagamento", pois trouxe inicialmente alíquotas de $1,5 \%$ a 2,5\% incidentes sobre a receita bruta e com redução para $1 \%$ e $2 \%$, respectivamente, a partir de $1^{\circ}$ de agosto de 2012 .

\subsection{Escrituração Fiscal Digital - Social (EFD-Social)}

Uma iniciativa proveniente do Programa de Aceleração do Crescimento (PAC) do Governo Federal, a EFDSocial, está em fase inicial do projeto e provavelmente quando for desenvolvido o leiaute, serão realizados os testes para lançamento do piloto, como é de costume a RFB proceder, utilizando contribuintes que se dispõem a participar e colaborar com as melhorias necessárias.

Não há material publicado, somente uma apresentação em slides da demonstração do projeto criado pela RFB, disponibilizado pelo site SPEDITO que traz os objetivos estratégicos propostos, dos quais se podem destacar: elevar a percepção de risco e a presença fiscal; aproximar a arrecadação efetiva da potencial.

O governo pretende incorporar no SPED toda a parte de escrituração da folha de pagamento a princípio e, posteriormente, o livro registro de empregados.

\section{METODOLOGIA}

0 presente estudo, com relação à forma de abordagem do problema, caracteriza-se como qualitativo. Segundo Gil (1996), a abordagem qualitativa não requer o uso de métodos e técnicas estatísticas, o ambiente natural é a fonte direta para coleta de dados e o pesquisador é o instrumento-chave. De acordo com Godoy (1995), a abordagem qualitativa busca descobrir como as noções se instalam, qual a qualidade dos processos interativos e como um fato singular pode adquirir relevância relativamente aos contextos mais amplos.

Quanto ao objetivo do estudo, refere-se à tipologia descritiva. Beuren (2003) afirma que esta tem como principal objetivo descrever as características de determinado fenômeno.

Como a pesquisa foi desenvolvida e embasada com estudo da legislação federal e estadual em vigor, com foco na sistemática do programa SPED dos governos federal e estadual e nos novos projetos previstos na legislação, no que diz respeito aos seus objetivos, classifica-se como descritiva e, do ponto de vista dos 
procedimentos técnicos, considera-se um estudo bibliográfico. Gil (1996) menciona que a pesquisa bibliográfica é elaborada tendo com base em material já publicado, constituído principalmente de livros, artigos de periódicos e atualmente com material disponibilizado na internet. Complementa Beuren (2003) que este tipo de procedimento explica um problema com base em referências teóricas.

\section{CONSIDERAÇÕESFINAIS}

A preocupação das empresas no que concerne ao cumprimento das obrigações perante o fisco federal, estadual e municipal tem crescido expressivamente nos últimos tempos. 0 governo vem desenvolvendo e inovando a cada ano seus controles e métodos de fiscalização, tendo apresentado significativa guinada com o desenvolvimento do SPED e de seus subprojetos.

Com as informações em meios magnéticos, recebidas periodicamente dos contribuintes, inclusive os livros fiscais e contábeis com as EFD Fiscal e Contribuições e a ECD armazenadas nos seus bancos de dados, é possível executar o cruzamento das informações, efetuando a auditoria eletrônica, que, por um simples comando, verifica as inconsistências entre as declarações dos contribuintes.

Esta pesquisa, de acordo com o seu objetivo geral, possibilitou estudar e descrever a estrutura do sistema público de escrituração digital e das novas obrigações pertinentes, que é o mais avançado modelo já desenvolvido pelo governo brasileiro. Observa-se que este, além de tornar célere o processo fiscalizatório, diminuirá, com o passar do tempo, o chamado "trabalho extra" desenvolvido pelos profissionais de contabilidade. Atualmente, perde-se muito tempo somente alimentando o fisco com diversas informações (por vezes redundantes) por ele exigidas, mensal ou anualmente, e, assim, deixando muitas vezes, em segundo plano, outras áreas a serem exploradas no exercício da profissão, como exemplo a contabilidade gerencial, que é imprescindível para o acompanhamento, gestão e crescimento dos empreendimentos.

O desenvolvimento do presente estudo, com base na bibliografia e legislação pesquisadas, possibilitou chegar às seguintes considerações:

a) 0 Governo Federal está investindo fortemente em ferramentas tecnológicas de apoio à fiscalização, principalmente no que tange ao aprimoramento do SPED.

b) Existem duplicidades de informações no que diz respeito ao novo panorama do SPED e às obrigações acessórias antigas, como DIPJ e DACON, as quais a RFB estuda gradativamente dispensar.

c) Estão sendo executados novos estudos pela RFB para inclusão de outras informações no contexto do SPED, fazendo com que os contribuintes sigam a legislação e cumpram as exigências, fechando, dessa forma, o cerco aos sonegadores que poluem o mercado e estimulam a concorrência desleal.

Conclui-se que o SPED, em conjunto com os seus subprojetos, trouxe significativas mudanças nas rotinas administrativas das empresas de todo o país e, consequentemente, diversos benefícios para a sociedade, pela fiscalização eletrônica mais eficaz. Toda a escrituração (fiscal e contábil) será disposta em forma digital ao fisco, elevando ainda mais o grau de responsabilidade por parte dos profissionais contábeis.

Finalmente, a pesquisa demonstrou que o governo criou uma forma muito eficaz de fiscalizar de maneira eletrônica e eficiente, valendo-se de tecnologia de última geração para auditar as empresas que se encontram na obrigatoriedade desse ambiente tecnológico e que estão tentando cumprir as novas exigências e obrigações acessórias criadas pelo fisco.

O SPED veio como um projeto e hoje é realidade ímpar e sem volta, com diversos subprojetos em desenvolvimento. Tornou-se, sem dúvida, a mais preciosa e poderosa ferramenta de fiscalização, trazendo benefícios para o meio empresarial, como a redução da concorrência desleal e, em extensão, melhorias para toda a sociedade. 


\section{THE STRUCTURE OF THE PUBLIC DIGITAL BOOKKEEPING SYSTEM (SPED): a study of new obligations}

\section{ABSTRACT}

The Public Digital Bookkeeping System (SPED) has been created by the government as an instrument for monitoring and supervision, aiming to promote the integrated systems of the tax authorities by standardization and sharing of information and tax accounting. A range of information to be reported periodically to the supervision has been one of the companies' major concern, emphasizing that relevant changes are being made by the new system impacting directly on such obligations. Thus, this study aims to describe the structure of SPED project and new relevant obligations laid down in customs legislation. Regarding the problem issue it has a qualitative nature. As the research was developed and based on federal and state legislation in force, it has been classified as descriptive towards its objectives, and technically seen as a literature study. The conclusions reveal that the tax authorities have structured the SPED effectively and with legal validity by electronic signature, enabling better exchange of tax accounting. It also became clear the lack of discontinuity on delivery requirement of previous ancillary obligation, resulting in data duplicity.

Keywords: The Public Digital Bookkeeping System. Ancillary obligations. Digital Tax assessment.

\section{REFERÊNCIAS}

BEUREN, I. M. Como elaborar trabalhos monográficos em contabilidade: teoria e prática. São Paulo: Atlas, 2003.

BRASIL.Instrução Normativa RFB no 787, de 19 de novembro de 2007. Institui a Escrituração Contábil Digital. Diário Oficial da União, Brasília, 20 de novembro de 2007. Disponível em:

< http://www.receita.fazenda.gov.br/legislacao/ins/2007/in7872007.htm>. Acesso em: 19 set. 2012.

BRASIL.Instrução Normativa DNRC no 107, de 23 de maio de 2008. Dispõe sobre a autenticação de instrumentos de escrituração dos empresários, sociedades empresárias, leiloeiros e tradutores públicos e intérpretes comerciais. Diário Oficial da União, Brasília, 30 de maio de 2008. Disponível em: < http://www.normaslegais.com.br/legislacao/indnrc107_2008.htm>. Acesso em: 19 set. 2012.

BRASIL. Instrução Normativa RFB no 1.218, de 21 de dezembro de 2011. Altera a instrução normativa RFB nº 1.052, de 5 de julho de 2010.Diário Oficial da União, Brasília, 22 de dezembro de 2011. Disponível em: < http://www.receita.fazenda.gov.br/legislacao/ins/2011/in12182011.htm> . Acesso em: 19 set. 2012.

BRASIL. RECEITA FEDERAL DO BRASIL. Guia prático da escrituração fiscal digital da Contribuição para o PIS/PASEP, da COFINS e da contribuição Previdenciária sobre a receita bruta - EFD-contribuições. [2012]. Disponível em: <http://www1.receita.fazenda.gov.br/sistemas/efdcontribuicoes/download/Guia_Pratico_EFD_Contribuicoes_Versao_107.pdf>. Acesso em: 15 maio 2012.

BRITO, D. SPED Fiscal: SPED Fiscal agora é lei. [2011]. Disponível em: <http://www.netlegis.com.br>. Acesso em: 15 abr. 2012.

DUARTE, R. D. Big brother fiscal - III: o Brasil na Era do Conhecimento. Minas Gerais: Ideas Work, 2009.

FAVERO, H. L. et al. Contabilidade: teoria e prática. 5. ed. São Paulo: Atlas, 2009.

GIL, A. de L. Sistemas de informações: contábil, financeiros. São Paulo: Atlas, 1992.

GIL, A. C. Como elaborar projetos de pesquisa. 3. ed. São Paulo: Atlas, 1996. 
GIROTTO, M. Sped contábil, o novo paradigma. Revista Brasileira de Contabilidade, Brasília, v. 37, n.170, p.7-11, mar./abr. 2008.

GODOY, A. S. Pesquisa qualitativa: tipos fundamentais. Revista de Administração de Empresas, São Paulo, v. 35, n. 3, p. 20-29. maio/jun. 1995.

HASTINGS, David F. Bases da contabilidade: uma noção introdutória. São Paulo: Saraiva, 2007.

IUDÍCIBUS, S. de. Teoria da contabilidade. 5. ed. São Paulo: Atlas, 1997.

MARIANO, P. A.; AZEVEDO, O. R. SPED: sistema público de escrituração digital. São Paulo: Iob, 2009.

MOSCOVE, S. A.; SIMKIN, M. G.; BAGRANOFF, N. A. Sistemas de informações contábeis. São Paulo: Atlas, 2002.

REIS, A. de J.; SILVA, S. L. da. A história da contabilidade no Brasil. Seminário Estudantil de Produção Acadêmica, v.11, n.1, p.1-13, 2007. Disponível em:

<http://revistas.unifacs.br/index.php/sepa/article/view/299/247>. Acesso em: 24 set. 2012.

STAINER, A. Productivity and strategic management accounting. International Journal of Technology Management, London, v. 13, n. 1, p. 57-67, 1997.

YOUNG, L. H. B. SPED: Sistema Público de Escrituração Digital. Curitiba: Juruá, 2009. 